\title{
DOBLE GÉNERO DISCURSIVO EN LA SAGRADA FAMILIA.
}

\section{DOUBLE GENDER DISCURSIVE IN THE SAGRADA FAMILIA.}

Olivier Gérard Angel Méric, PhD.

Doctor en letra moderna (Francia).

Docente investigador de la Universidad Estatal Amazónica, Ecuador. olivier.meric.a@gmail.com

Angélica Leticia Cahuana Velasteguí, MSc. Máster en Arte, Letra y Lengua mención especialista en Ciencia del lenguaje y didáctica del francés (Francia). Docente de Francés, Ecuador. aleticv@hotmail.com

\section{ARTÍCULO DE INVESTIGACIÓN}

Recibido: 4 de octubre de 2017

Aceptado: 12 de diciembre de 2017

\section{RESUMEN}

El artículo se enfoca en la descripción de los géneros discursivos utilizados en un contexto turístico donde el investigador analiza dos discursos diferentes de un mismo lugar turístico: la Sagrada Familia en Barcelona. El objetivo es de definir el género de discursos específicos relacionados con diferentes prácticas profesionales: la visita guiada con presencia física del experto, y la visita guiada con la ayuda de un aparato socio-técnico donde se grabó la información, con el afán de descubrir sus características y medir el impacto sobre la percepción cultural de los participantes. La metodología aplicada se fundamenta en la teoría de las estructuras retóricas de Mann \& Thomson que permite al investigador diseñar la organización textual etiquetando las relaciones establecidas entre las diferentes contribuciones del locutor. Los resultados brindaron una descripción detallada de la 
organización textual ofreciendo insumos que podrían ser útiles para los profesionales del turismo.

Palabras clave: lingüística de corpus, análisis del discurso, género, discurso profesional.

\section{ABSTRACT}

This paper focuses on professional genre discourse description applied in tourism context where two different service modalities allows the researcher to deal with two different discourses of the same touristic place: the Sagrada Familia in Barcelona. The aim is to define the genre of the specific discourse related to the different professional practices: the guided visit with the physical presence of an expert, and the guided visit using a sociotechnical device where the information is recorded, in order to acknowledge its characteristics and measure the impact on cultural perceptions. The applied methodology relies on the Mann \& Thomson's Rhetorical Structure Theory which allows the researcher to design the text organisation by labelling the relations set between the different locutors' contributions. The results give a detailed description of the text organisation offering outcomes which could be useful for professional involved in tourism field.

Keywords: corpus linguistics, discourse analisis, genre, professional discourse

\section{INTRODUCCIÓN}

La innovación continua en el dominio de la tecnología de la información y de la comunicación ofrece nuevas modalidades de prestaciones de servicio en los diferentes sitios turísticos como son los museos. Dentro de un cuadro institucional el diseño de las diferentes modalidades de las visitas guiadas debe conciliar el discurso institucional con las expectativas de los turistas ofreciendo diferentes alternativas. Las estrategias de comunicación brindan al visitante varias modalidades con el afán de diversificar las experiencias de interactividad con las obras expuestas. En este contexto, este estudio describe y compara el discurso producido en la visita guiada del templo expiatorio de la Sagrada Familia con el discurso del audio-guía del mismo lugar. 
Las dos modalidades comentan el mismo recorrido garantizando al investigador que las variaciones discursivas observadas son principalmente debidas al modo de difusión. El presente trabajo tiene el objetivo de evidenciar que los discursos son suficientemente diferentes para representar dos identidades: una institucional y otra personal, a través de la difusión de dos géneros discursivos. Con la ayuda de la lingüística de corpus (Biber, 1993a, 1993b; Biber et al., 1998; Sinclair, 1991; Tognini-Bonelli, 2001), el propósito es de evidenciar cómo las características extra-lingüísticas y lingüísticas del discurso profesional reflejan las diferentes percepciones culturales y sociales. Por consecuencia, es importante entender cómo el discurso de dos modalidades de visita de un entorno museístico ayuda al visitante a construir una interpretación de la obra de arte. Entonces, el estudio se enfoca sobre las características del discurso producido en la interacción entre el guía y los visitantes, y sobre las características del discurso escrito por las grabaciones del audio-guía con el afán de determinar cómo las condiciones extra-lingüísticas de una práctica profesional modifican el discurso. El segundo objetivo es demostrar que la aplicación de una metodología pragma-semántica en el análisis discursivo puede evidenciar diferencias extra-lingüísticas tanto culturales como identitarias.

En primer lugar, se describe los géneros discursivos relativos a las modalidades de visitas antes de presentar la teoría de las estructuras retóricas (Mann \& Thomson, 1987, 1988; Mann et al. 1992; Taboada \& Mann, 2006a, 2006b) que dentro de una concepción postgriceana (Portugués, 2011; Borderieux, 2013) es utilizada como herramienta analítica para la caracterización del género discursivo de las modalidades de visitas. En la última parte se comunicará las posibles implicaciones que las modalidades de prestaciones de servicios tienen sobre las características culturales e identitarias del discurso compartido.

\section{REVISIÓN TEÓRICA}

\section{Géneros del discurso profesional de la visita guiada}

Los textos seleccionados en este estudio se producen en contexto profesional con objetivos específicos. Según Gunnarsson el sintagma "discurso profesional" se refiere a los textos producidos "en contextos profesionales con propósitos profesionales"1 (2009, p. 5). Con respeto a la visita guiada, el guía es el profesional que interactúa con los visitantes; en la

\footnotetext{
${ }^{1}$ Salvo indicaciones contrarias, las traducciones al español son propuesta por el autor y la versión original se consignará en nota de pie de página: "in professional contexts and for professional purposes".
}

ISSN: 1390-9320, Vol. 5, No. 1, febrero 2018 
visita audio-guiada, el visitante conserva su estatus pero el profesional se identifica como el autor del texto escrito para la grabación. Gunnarsson considera que "existen géneros específicos relacionados con las actividades profesionales específicas a situaciones específicas, que también conllevan las características discursivas normalizadas"2 (2009, p. 9). En acuerdo con Drew \& Heritage (1992), Koester introduce el concepto de "conversación institucional" ${ }^{3}$ diferente de la conversación ordinaria por sus objetivos relacionados con propósitos profesionales y por las diferentes posiciones que el locutor tiene lo que presenta un impacto directo en el turno de palabra y en la legitimidad de cada contribución. En otros términos, lo que determina un género discursivo no viene únicamente de las características lingüísticas sino también de factores retóricos dependientes del contexto profesional de producción del discurso. Según Berkenkotter \& Huckin (1995), las interacciones sociales se formalizan en los géneros discursivos, y por otro lado, los géneros discursivos moldean las prácticas comunitarias, por ende los textos seleccionados tienen los rasgo del contexto social en el cual fueron construidos.

Para categorizar los textos en diferentes géneros discursivos, se consideró los aspectos comunicativos, cognitivos y formales con el afán de asentar la taxonomía sobre diferentes criterios sociolingüísticos:

a) Dentro del aspecto comunicativo, se consideró el estatuto del locutor y los objetivos de la comunicación como informar, entretener, vender, etc., antes de considerar las diferentes prácticas profesionales.

b) Al nivel cognitivo se consideró el principio de completud de portugués para definir la pertinencia de las contribuciones (2011).

c) El aspecto formal integra la organización estructural evidenciada por el tratamiento analítico de la teoría de las estructuras retóricas.

Tomando en cuenta la doble naturaleza de los textos constitutivos del corpus compilado por el estudio, un discurso redactado de ser grabado y un discurso de interacción oral, es

\footnotetext{
2"specific genres are attached to specific professional activities in specific situations, which often also entails conventionalized discourse patterns".

3"institutional talk"
} 
necesario considerar la contribución ${ }^{4}$ como una unidad semántica de segmentación óptima para los dos discursos. Portugués introduce la noción de contribución:

La contribución es una producción propia del locutor que tiene el afán de trasmitir con una eficiencia máxima la información a un receptor. La comunicación entre los dos interlocutores se apoya en el planteamiento de que el locutor debe contribuir, es decir formar una contribución que tendrá todos los elementos que permitan al receptor de entender cuál es la información que el locutor desea trasmitir ${ }^{5}$ (2011, p. 89).

Entonces los textos están segmentados en contribuciones cuya completud pragmasemántica y la pertinencia ${ }^{6}$ permiten al receptor atento adquirir todo la información requerida para interpretar el mensaje recibido, como lo ilustra el siguiente ejemplo ${ }^{7}$ (cada línea contiene una y una sola contribución):

(1) hay una escultura de bronce que representa a San Jorge

el patrón de Cataluña

es obra de Josep María Subirachs

Respetando a los tres aspectos antes mencionados y la práctica profesional se propone, en el cuadro 1, una taxonomía de la familia "interpretación cultural" de los géneros discursivos según los trabajos de Calvi (2010, p. 22):

\footnotetext{
${ }^{4}$ El sintagma "contribución"se refiere a la palabra utilizada por Grice en la definición de sus máximas: "Make your contribution such as it is required, at the stage at which it occurs, by the accepted purpose or direction of the talk exchange in which you are engaged." (Grice, 1975)

${ }^{5}$ La contribution est une contrainte propre à l'énonciateur et qui a pour but de transmettre avec une efficacité maximale l'information à un interprétant. La communication entre les deux interlocuteurs repose sur le postulat selon lequel l'énonciateur doit contribuer, c'est-à-dire former une contribution qui aura tous les éléments permettant à l'énonciateur de saisir quelle est l'information que l'énonciateur souhaite transmettre

${ }^{6}$ Se refiere a la teoría de la pertinencia de Sperber \& Wilson (2004, p. 62)

${ }^{7}$ Todos los ejemplos presentados vienen del corpus compilado. En este estudio se usa una trascripción ortográfica sin aplicar correcciones sintáctica, gramatical, o estructural. Salvo la presencia de los puntos de interrogación y de exclamación, no se presentan otras formas de puntuación.
}

ISSN: 1390-9320, Vol. 5, No. 1, febrero 2018 
Tabla 1. Taxonomía de los géneros discursivos.

\begin{tabular}{|l|l|l|}
\hline Discurso especializado del Turismo \\
\hline Tipo & Nombre & Criterios \\
\hline Familia de géneros & - Interpretación cultural & Campo de actividad \\
\hline Macro-géneros & - Visitas guiadas & Modo operatorio \\
\hline Géneros & $\begin{array}{l}\text { - Visita con guía turístico } \\
\text { - Visita con audio-guía }\end{array}$ & $\begin{array}{l}\text { Situación } \\
\text { comunicación }\end{array}$ \\
\hline
\end{tabular}

Fuente: Elaboración propia.

El criterio más destacado para determinar la familia de géneros es el campo de actividad en el cual el ámbito semántico se define según la función social del locutor y las intenciones de comunicación. Por ende, esta familia de géneros integra los discursos correspondientes a una comunicación entre un profesional del turismo y los visitantes; las intenciones de comunicación son: entretener, satisfacer e informar. El modo operatorio que se practica usualmente en esta familia de géneros se define según criterios institucionales: contexto discursivo, modalidad de interacción, canal de comunicación, etc. El último criterio extralingüístico para determinar los géneros discursivos es la situación de comunicación propia dado que "Es en este nivel donde se empiezan a discernir los rasgos lingüísticos distintivos" (Calvi, 2010, pp. 24-25). En el presente trabajo, la dimensión sociolingüística del aspecto comunicativo permite proponer a priori dos géneros: la "visita con guía turístico" y la "visita con audio-guía". La organización textual y la ocurrencia de los fenómenos pragmasemánticos serán los criterios lingüísticos relacionados al aspecto formal y cognitivo para evidenciar a posteriori la distinción propuesta.

Según Biber (1993ª , p. 245), el cuadro 2 presenta los diferentes parámetros de los criterios que fueron seleccionados para posicionar a priori el discurso en la taxonomía precedente.

Tabla 2. Parámetros de los discursos estudiados.

\begin{tabular}{|l|l|l|}
\hline Parámetros & Visita con guía turístico & Visita con audio-guía \\
\hline Canal de producción & Oral & Escrito \\
\hline Canal de enunciación & Oral & Oral \\
\hline Formato & efémero & perene \\
\hline
\end{tabular}


Revista Científica ECOCIENCIA

\begin{tabular}{|c|c|c|}
\hline Contexto & Institucional & Institucional \\
\hline Audiencia & Adultos & Adultos \\
\hline Número & Grupo & Individual \\
\hline Asistencia & Presente & $\begin{array}{l}\text { Ausente cuando el texto está } \\
\text { producido }\end{array}$ \\
\hline Interacción & Directa y sincrónica & $\begin{array}{lll}\text { aparato } & \text { socio-técnico } \quad y \\
\text { asíncrona } & & \end{array}$ \\
\hline Autor & Guía & escritor profesional \\
\hline Locutor & Guía & Actor \\
\hline Funciones & Describe, informa, entretiene & Describe, informa, entretiene \\
\hline Temática $^{8}$ & Visita turística cultural & Visita turística cultural \\
\hline Situación geográfica & Sagrada Familia & Sagrada Familia \\
\hline Período & Agosto 2014 & Agosto 2014 \\
\hline $\begin{array}{l}\text { Tiempo de grabación y } \\
\text { número de signos }\end{array}$ & $\begin{array}{l}40 ' 50 " \\
7083 \text { tokens }\end{array}$ & $\begin{array}{l}45^{\prime} \text { ( } 75^{\prime} \text { including music) } \\
4874 \text { tokens }\end{array}$ \\
\hline
\end{tabular}

Fuente: Elaboración propia.

La clasificación precedente establece las necesarias bases para una verificación a posteriori de la caracterización del género discursivo de las modalidades de visitas. Gunnarsson asienta que "los profesionales escribe y hablan según las características del género que aprendieron e internalizaron en sus prácticas y en sus socializaciones ${ }^{9 "}$ (2009, p. 43), el uso de la teoría sobre las estructuras retóricas (RST) ayuda a comprobar su afirmación en asignar nombre a las relaciones existentes entre las contribuciones como ilustrado en la figura 1:

\footnotetext{
${ }^{8}$ Los cuatros últimos parámetros son propios al diseño del presente estudio.

9 "professionals write and talk in accordance with the genre patterns which they have learnt and internalized as a part of their training and socializing."
}

ISSN: 1390-9320, Vol. 5, No. 1, febrero 2018 


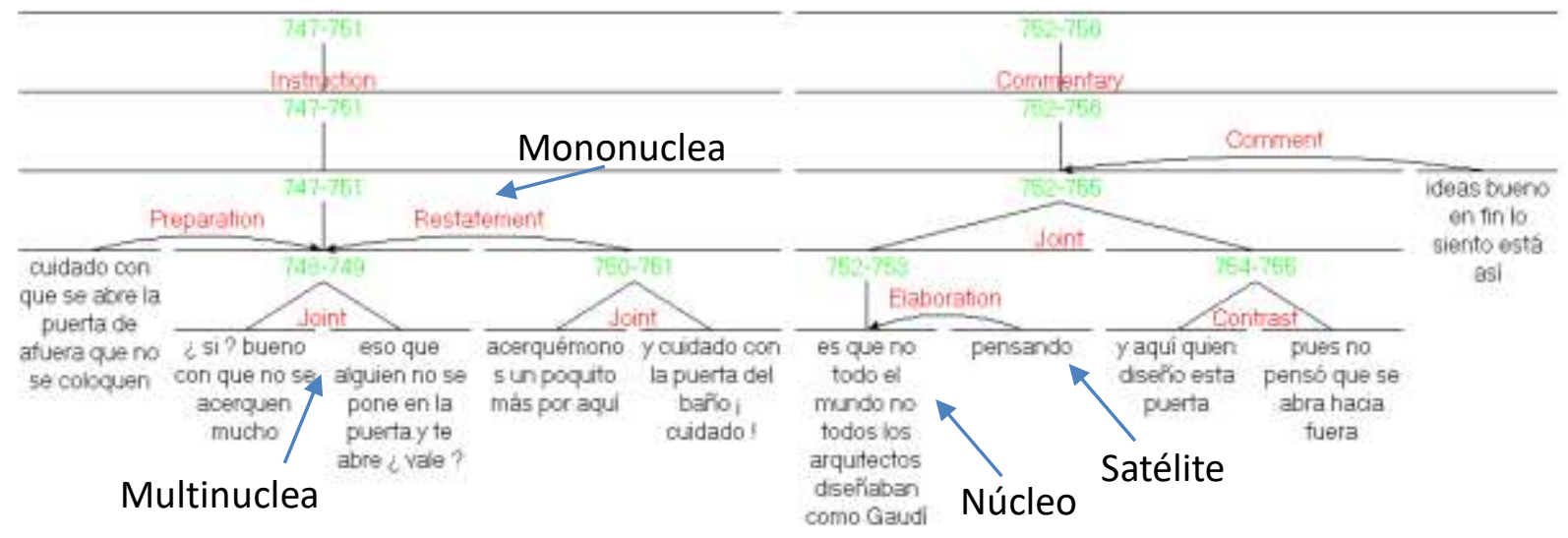

Figura 1. Ejemplo de anotación textual en RST.

Fuente: Elaboración propia.

Según Taboada \& Mann, identificar las relaciones entre las contribuciones permite resaltar la coherencia y la cohesión del texto (2006aㅗ , p. 428). Los autores brindan 32 definiciones divididas en relaciones mononucleadas y multinucleadas (Mann \& Thompson, 2005-2015); de las definiciones propuestas, en este estudio se utilizó 6 multinucleadas (Contrast, Joint, List, Sequence, Choice, y Simultaneity) y 15 mononucleadas (Background, Cause, Comment, Condition, Elaboration, Evidence, Inquiry, Means, Motivation, Purpose, Preparation, Restatement, Result, Solutionhood, Summary) ${ }^{10}$. Para completar la organización textual se considera 5 esquemas (Commentary, Contact, Information, Instruction, Reaction) en los cuales se agrupan las relaciones según las siguientes definiciones:

- Commentary: grupo estructural de contribuciones compartiendo con la audiencia una opinión o una interpretación del tema de comunicación.

- Contact: grupo estructural de contribución es estableciendo una relación entre los interlocutores para saludar, presentar una persona o despedirse.

- Information: grupo estructural de contribuciones compartiendo con la audiencia datos sobre el tema de la comunicación.

- Instruction: grupo estructural de contribuciones induciendo una modificación del comportamiento de la audiencia según las intenciones del locutor.

${ }^{10}$ Recuperado de http://www.sfu.ca/rst/01intro/definitions.html 
- Reaction: grupo estructural de contribuciones relacionadas con intervenciones espontáneas interrumpiendo el flujo de la comunicación en curso.

En la ilustración precedente (figura 1) se encuentran dos ejemplos de los esquemas considerados: Instruction y Commentary.

\section{ANÁLISIS DE RESULTADOS}

\section{Análisis textual}

Comparando las características de los textos desde un enfoque general hacia una información detallada, se empieza con la distribución de los esquemas que organizan la estructura textual (figura 2):
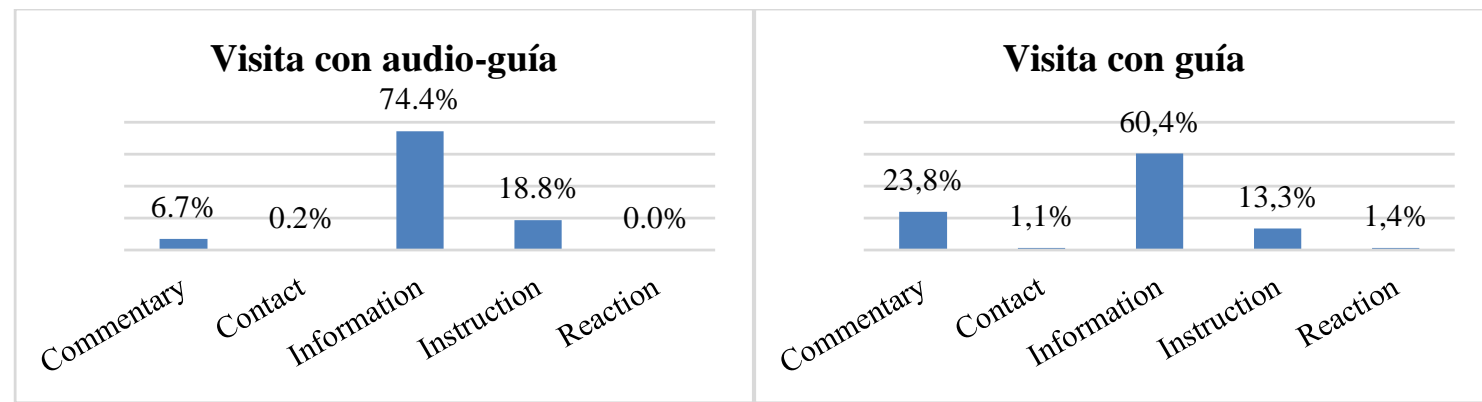

Figura 2. Distribución de los esquemas en las dos modalidades de vistas.

Fuente: Elaboración propia.

La mayor diferencia se observa en el esquema Commentary con $17.1 \%$. Según la definición, es donde se expresa la subjetividad del locutor, refleja el discurso en el cual el locutor es también autor de sus palabras en contraste con un discurso oficial donde, por ejemplo, el locutor es el guía o el actor y el autor la institución. Se corrobora esta diferencia con los $14.0 \%$ que separan los esquemas Information de las dos modalidades, en los cuales se encuentran la información académica, histórica y objetiva que la institución desea comunicar. Se sugiere que el guía en una comunicación directa cara a cara puede compartir su sentir sobre la obra haciendo resaltar su contexto cultural, cuando el discurso 
institucional del audio-guía tiene que complacer una audiencia más amplia que los miembros de un grupo de visitantes.

Los 5.5\% de diferencia en el esquema Instruction coinciden con la ausencia física del guía dando que en su presencia el lenguaje corporal acompaña las instrucciones de desplazamiento mientras en el discurso del audio-guía se deben brindar instrucciones detalladas para asegurarse que el centro deíctico del visitante coincide con el comentario grabado. En la modalidad de visita con el guía, el esquema Contact es más desarrollado dando que el experto debe identificarse como tal, "romper el hielo", y en este caso presentar el investigador:

(2) pues buenos días a todos

bienvenidos bienvenidas a la visita de la Sagrada Familia soy Cristina $B$.

soy ya oficial de turismo en Cataluña

y también les presente a Olivier porque le van a ver con esto aparatito está haciendo una investigación sobre la interacción del guía y el grupo así que va a gravar la voz creo nada más y es anónimo ${ }^{11}$

En esta situación comunicativa, según Hall y su teoría de la proxémica (1966), el público se encuentra en la zona social del guía en la cual se necesita identificar los locutores con nombre, apellido y funciones sociales, mientras en la situación del audio-guía, el hecho de poner los audífonos transporta el comentador en el espacio íntimo del visitante en el cual los locutores no tiene que seguir un protocolo social para establecer una relación, el locutor puede directamente entrar en el tema central:

\footnotetext{
${ }^{11}$ Muestra de la transcripción de la visita guiada con el guía.
} 
(3) le invitamos a escuchar unas palabras de bienvenidas del señor Esteve Camps presidente delegado bienvenidos a la basílica de la Sagrada Familia ${ }^{12}$

Siendo un esquema que representa una interacción directa y sincrónica, la ausencia de Reaction en la modalidad del audio-guía es lógica y no necesita más explicaciones.

Al nivel de las relaciones multinucleadas se observa diferencias significativas en las relaciones Contrast (20\%) y Sequence (13.3\%).

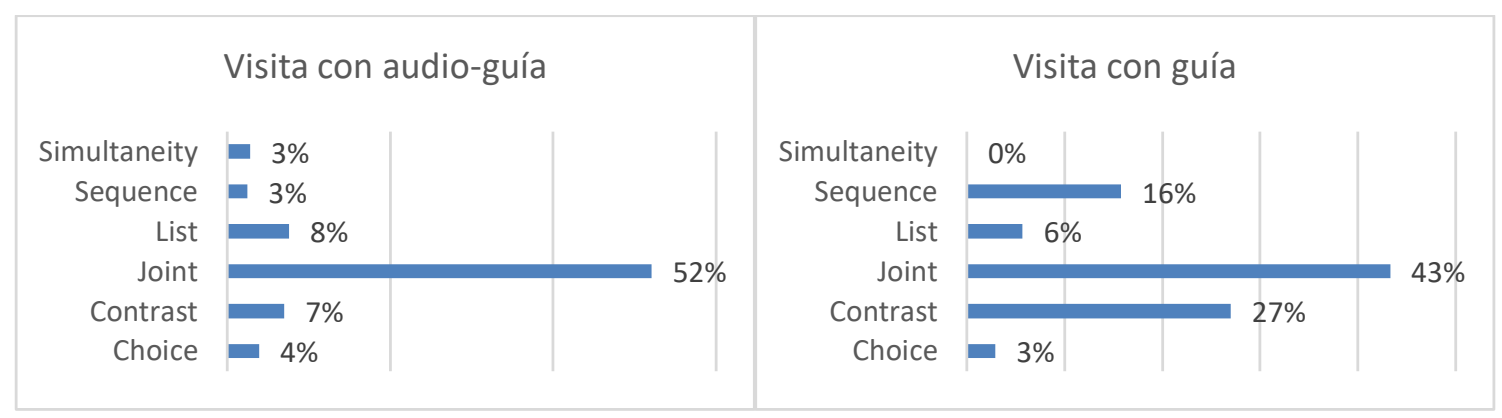

Figura 3. Distribución de las relaciones multinucleadas.

Fuente: Elaboración propia.

Tomando en cuenta la definición de la relación Contrast, el visitante identifica una oposición entre dos contribuciones. Con el audio-guía, estas oposiciones son positivas o al menos neutras:

(4) pese a las varias dificultades que a lo largo de los años cautelaron el ritmo de su construcción

\footnotetext{
${ }^{12}$ Muestra de la transcripción de la visita guiada con el audio-guía.
} 
se ha hecho realidad el sueño de varias generaciones

(5) si las fachadas laterales se centran en la figura de Jesús

la de la gloria interpela directamente al creyente

En la visita con el guía ${ }^{13}$, se presentan oposiciones de connotaciones más negativas introduciendo un discurso menos "políticamente correcto" favoreciendo el discurso personal en contradicción con el discurso oficial:

(6) ni el arquitecto Gaudí tampoco ha querido dar más información

pero eso es un tema que afecta el ayuntamiento

es municipal no a mi

ya tengo suficiente con esto

(7) como se pueden imaginar Gaudí era católico

y muy muy creyente

y de misa diaria Antonio Gaudí

no todo el arquitecto que está aquí necesariamente lo es

pero en su caso sí.

Con respeto a la relación multinucleada Sequence, en el discurso del guía se observa una facilitad para referirse a los parámetros espaciales y temporales dando que no existe confusiones posibles en la ubicación del centro deíctico del discurso. Por ende, el locutor puede referirse a estos parámetros compartidos para desarrollar explicaciones secuenciales, mientras en el audio-guía el discurso evita estas secuencias que necesitaría una ubicación constante del centro deíctico. Por otro lado, las secuencias en esta última modalidad se encuentran en las instrucciones:

\footnotetext{
${ }^{13}$ Cabe mencionar que el guía era nativo de Cataluña y que a través de su discurso demostraba una admiración para Antonio Gaudí.
}

ISSN: 1390-9320, Vol. 5, No. 1, febrero 2018 
(8) quítense las auriculares

siéntese

olvide sus preocupaciones cotidianas

y permítase unos minutos de introspección

El análisis de las relaciones mononucleadas describe el discurso del audio-guía como narrativo y explicativo que el discurso del guía turístico el cual aparece argumentativo con varios comentarios personales. Cabe recordar que el discurso del audio-guía tiene la especificidad de ser escrito para ser grabado, entonces, aún si el autor demuestra la voluntad de crear una cierta interactividad con el visitante, la modalidad de producción del texto le orienta a compartir más datos con explicaciones detalladas. Esta densidad de información puede inducir un comportamiento de saturación teniendo por efecto un rechazo del audio-guía dando que el visitante puede preferir la conexión con la obra que vino a visitar a prestar atención al discurso enciclopédico.

En la modalidad de visita con el guía constan varias intervenciones del experto revelando sus preferencias identitarias (9); critica abiertamente la institución (10) y la obra (12), se vuelva impaciente con los visitantes que toman fotografías (11), y es irónica con el grupo (13) y (14).

(9) y que eso si es traje típico catalán

(10) tenemos un pequeño accidente también con la mano de Jesús trabajando como carpintero

allí también hace un poco falta de restauración

(11) j ah bueno ! esperando la foto ya está

(12) es mucho más austera

(13) no se sientan ridículos

(14) no va a caer. 
El análisis de la distribución de las relaciones mononucleadas informe sobre las tendencias del discurso en cuanto a su carácter explicativo, argumentativo, descriptivo o interactivo.

Los fenómenos descritos caracterizan los dos discursos representativos de las modalidades de prestación de servicios en oferta a la Sagrada Familia asentando sus diferencias para categorizarlos en dos géneros discursivos diferentes.

\section{CONCLUSIONES}

El objetivo de este estudio es presentar una metodología de análisis discursiva que, con la ayuda de herramientas pragmáticas como la RST, permite determinar las características organizacionales del discurso relacionado a prácticas socio-profesionales. El proceso seguido conduce a la modelización de cómo los parámetros extra-lingüísticos influyen en la organización textual del discurso; de hecho, compartir una opinión personal en una interacción directa con un grupo de visitantes es tanto pertinente como encontrar un discurso más académico en el audio-guía dando que el mensaje se dirija a un público más amplio, pero se pierde toda pertinencia si estas características se encuentran en el discurso equivocado. En la situación de comunicación elegida para este estudio, a pesar de tener temas idénticos aparecen diferencias significativas para concluir que el discurso no está dirigido a un público que tiene las mismas experiencias con las obras de arte: cada visitante adaptará su modalidad de visita a sus preferencias con la esperanza de encontrar el discurso que satisface sus expectativas.

Aunque el proceso analítico se apoya en etapas empíricas y subjetivas cuando se segmenta el texto en contribuciones y se elige las relaciones que denominan los enlaces entre las contribuciones, el tratamiento estadístico evidencia las principales características de la modalidad considerada y brinda al investigador resultados que pueden tener aplicaciones directo en el ámbito profesional del turismo. Si una institución desea evaluar el impacto de su discurso institucional u orientar el discurso de sus audio-guías hacía en público diferente, puede aplicar tal análisis para brindar las sugerencias necesarias a la redacción de nuevos textos en acuerdo con las políticas institucionales. 


\section{REFERENCIAS BIBLIOGRÁFICAS}

Berkenkotter, C.; Huckin, T. (1995). Genre Knowledge in Disciplinary Communication: Cognition/ Culture/ Power. Hillsdale: L. Erlbaum Associates.

Biber, D. (1993a). Representativeness in Corpus Design. Literary and Linguistic Computing, Volumen V. (8/4) 1993, pp. 243-257.

Biber, D. (1993b). Using register-diversified corpora for general language studies. Computational Linguistics, Volumen V.(19/2) 1993, pp. 219-241.

Biber, D.; Conrad, S.; Reppen R. (1998). Corpus Linguistics: Investigating language structure and use. Cambridge: Cambridge University Press.

Borderieux, J. (2013). La construction textuelle du brevet d'invention: analyse et théorisation de la strate contributionnelle.Tesis doctoral, Universidad de Orléans, Francia.

CALVI, M.V. (2010). LOS GÉNEROS DISCURSIVOS EN LA LENGUA DEL TURISMO: UNA PROPUESTA DE CLASIFICACIÓN. IBERICA, VOLUMEN V. (19) 2010, PP. 9-31.

Drew, P.; Heritage, J. (1992). Analyzing Talk at Work: An Introduction. Talk at Work, Cambridge: Cambridge University Press, pp. 3-65.

Gunnarsson, B-L. (2009). Professional Discourse. London ANd NEW YoRK: ContinUUm INTERNATIONAL PUBLISHNIG GROUP.

Mann, W. C.; Matthiessen, C. M. I. M.; Thompson S. A. (1992). Rhetorical Structure Theory and text analysis. Discourse description: Diverse Linguistic Analyses of a FundRaising Text, Mann W.C. \& Thompson S.A. (eds), Amsterdam: John Benjamins, pp. 39-78.

Mann, W. C.; Taboada, M. (2005-2015).Les définitions des relations de la RST.recuperado el 05 de noviembre 2017. http://www.sfu.ca/rst/07french/definitions.html

Mann, W. C.; Thompson, S. A. (1987). Rhetorical Structure Theory: A Theory of Text Organization. recuperado el 05 de noviembre 2017.http://www.sfu.ca/rst/pdfs/Mann_Thompson_1987.pdf 
Mann, W. C.; Thompson, S. A. (1988). Rhetorical Structure Theory: Toward a functional theory of text organization. Text, Volumen V. (8/3) 1988, pp. 243-281.

Portugués, Y. (2011).Contraintes pragmatiques de complétude et linguistique des contributions en théories du texte et de l'organisation textuelle : élaboration d'une heuristique appliquée au roman de formation. Tesis doctoral, Universidad deOrléans, Francia.

Sinclair, J. (1991). Corpus, Concordance, Collocation. Oxford: Oxford University Press.

Taboada, M.; Mann, W. C. (2006a) Rhetorical Structure Theory. Discourse Studies, Volumen V. (8/3) 1991, pp. 423-459.

Tognini-bonelli, E. (2001). Corpus Linguistics at Work. Amsterdam: John Benjamins, collection Studies in Corpus Linguistics. 